\title{
Palabras entre las bombas: crónicas sobre la guerra civil española de Pablo de la Torriente- Brau, Raúl González Tuñón y Juvencio Valle*
}

\author{
Jesús CANO REYES \\ Universidad Complutense de Madrid \\ jesuscanoreyes@filol.ucm.es
}

\begin{abstract}
RESUMEN
En el artículo se recorre el panorama de las crónicas enviadas por los escritores hispanoamericanos que se desplazaron a España como corresponsales de la guerra civil. La mayoría de estos textos, composiciones híbridas a medio camino entre la literatura y el periodismo (cuya frontera es más difusa de lo que pudiera parecer), se encuentran hoy en el olvido. Al tiempo que se indaga en la bibliografía sobre el tema y se propone una base teórica para analizar las crónicas, se muestran algunos ejemplos, destacando aquellos en los que el afán de búsqueda estética es más claro. Por cuestiones de espacio, el trabajo se centra en el cubano Pablo de la Torriente Brau, el argentino Raúl González Tuñón y el chileno Juvencio Valle.
\end{abstract}

Palabras clave: Crónicas, Pablo de la Torriente Brau, Raúl González Tuñón, Juvencio Valle.

\begin{abstract}
This article presents the panorama in which Spanish American writers who moved to Spain as Civil War correspondents produced their work. Most of these chronicles, now largely forgotten, are hybrid compositions that stand half way between literature and journalism (a rather obscure frontier). This paper examines bibliography on the subject, poses a theoretical basis of analysis and offers a set of examples which clearly pursue an aesthetic purpose. It does so by focusing on the work of the Cuban Pablo de la Torriente Brau, the Argentinian Raúl González Tuñón and the Chilean Juvencio Valle.
\end{abstract}

Keywords: Chronicles, Pablo de la Torriente Brau, Raúl González Tuñón, Juvencio Valle.

\footnotetext{
* Este trabajo ha sido posible gracias a la beca FPU concedida por el Ministerio de Educación (AP2009-1821) y al proyecto de investigación "El impacto de la Guerra Civil Española en la vida intelectual de Hispanoamérica" financiado por el Ministerio de Ciencia e Innovación (FFI2011-28618).
} 
1. Hasta el siglo XVII nadie lo había imaginado. Fue el físico francés Edme Mariotte el primero en demostrar que no es ojo todo lo que reluce: allí donde el nervio óptico conecta con la retina, no hay células sensibles a la luz; por lo tanto, es una zona de no visión, un punto ciego. Si no percibimos esta carencia, es sencillamente porque el cerebro completa la información con lo que capta el otro ojo.

La encrucijada que reúne a la literatura y al periodismo es el punto ciego del ojo crítico. Confiando en las teorías de Mariotte, el canon literario pensó que el periodístico completaría la falla, y viceversa, de modo que el desamparo ha perdurado y todavía no se ha resuelto la desinformación ${ }^{1}$. Territorios casi vírgenes, regiones inexploradas del mapa. Pese a ello, no se trata de lugares tan lóbregos y deshabitados como pudiera parecer, sino que albergan algunas familias de textos heterogéneos cuya confusa estirpe no impide el desarrollo de una brillante calidad. Purgada ya su culpa, el pecado original de su rareza, alzan los brazos para llamar la atención como el náufrago que reclama al avión el rescate de las tierras donde vive entre la invisibilidad y el olvido.

2. En 1936 el centro del mapa es España. Allí se juega una partida universal, el ensayo donde las dos grandes ideologías miden sus fuerzas para la conflagración que se avecina. España, cuyo nombre adquiere en la época resonancias legendarias, es sinónimo de miedo o esperanza para unos o para otros; para todos es sinónimo de fervor, pues nadie puede quedar al margen de los avatares de una guerra de la que depende el precario equilibrio del mundo.

El imán español, como es bien sabido, atrae a escritores e intelectuales de todo el mundo, que no quieren desoír los cantos de sirena de la gran epopeya de su tiempo. Celebrado en 1937 en Valencia, Madrid, Barcelona y París, el II Congreso Internacional de Escritores para la Defensa de la Cultura reúne bajo las bombas que buscan el corazón del pueblo a más de cien intelectuales que debaten sobre su papel en la lucha y logran una victoria simbólica para la República, si no en el frente de batalla, al menos sí en la retaguardia cultural ${ }^{2}$. A partir de esta guerra, surgen obras memorables de escritores extranjeros como Por quién doblan las campanas (1940), de Ernest Hemingway; La esperanza (1937), de André Malraux; Homenaje a Cataluña (1938), de George Orwell.

\footnotetext{
${ }^{1}$ Según Albert Chillón, a quien aludiré más adelante, esta carencia se debe a una doble razón: “...de un lado, historiadores y críticos literarios no han creído necesario ocuparse del periodismo, ni mucho menos de las conexiones que este guarda con la literatura; de otro, los estudiosos del periodismo y la comunicación, quizá a causa de la adolescencia de las disciplinas que cultivan, han menospreciado o simplemente soslayado la cuestión - a lo sumo, se han referido a ella de pasada, como quien habla de un tema menor.” A. Chillón (1999), p. 395.

${ }^{2}$ Sin lugar a dudas, la obra fundamental sobre este encuentro histórico es la trilogía de Manuel Aznar Soler y Luis Mario Schneider II Congreso Internacional de Escritores Antifascistas (1937), Barcelona; Laia, 1978-79.
} 
El hispanista Paul Preston, en su libro Idealistas bajo las balas, repasa la nómina de corresponsales extranjeros que viajan a España para contar al mundo lo que está sucediendo ${ }^{3}$. No hay nada extraño en que los corresponsales de guerra se desplacen allí donde se desata un conflicto para transmitir la información a todos los países; el hecho excepcional, sin embargo, consiste en que entre ellos se encuentran, intrusas (iintrusas?), muchas de las primeras plumas de la literatura que usurpan las columnas tradicionalmente elaboradas por los periodistas:

Junto con los corresponsales de guerra profesionales, algunos de ellos veteranos curtidos en Abisinia y otros cuya valía todavía estaba por demostrar, llegaron algunas de las figuras literarias más sobresalientes del mundo: Ernest Hemingway, John Dos Passos, Josephine Herbst y Martha Gellhorn de Estados Unidos; W. H. Auden, Stephen Spender y George Orwell de Gran Bretaña, y André Malraux y Antoine de Saint Exupéry de Francia. Algunos fueron en su condición de izquierdistas; otros, bastantes menos, como derechistas, e infinidad de los que pasaron breves períodos en España pensaban trabajar como reporteros de forma puntual ${ }^{4}$.

Pese a la sólida investigación y a la amena escritura, el libro resulta parcial, pues no hay en él ni una sola mención a los escritores hispanoamericanos, quienes igual que los otros ejercieron como corresponsales en España. Como Hemingway, como Orwell, como Saint-Exupéry, ellos también cuentan la guerra desde el lugar de los hechos. Sin embargo, la mayoría de sus crónicas, que son seguidas con entusiasmo por los lectores de la época, duermen hoy el sueño tan parecido a la muerte de las hemerotecas.

3. Unos pocos exploradores osados han viajado al punto ciego. Ha cobrado singular fortuna la reiterada cita de José Acosta Montoro, quien afirma que la literatura y el periodismo "son como la rama y el tronco, que no pueden vivir por separado" . El debate acerca de este vínculo íntimo ha estado presente, por lo menos en España, desde mediados del siglo XIX, cuando Joaquín Francisco Pacheco preguntaba en su discurso a la Real Academia: "¿Es verdaderamente el periodismo una rama fecunda de la literatura?"6. La nómina de autores que han jugado a dos bandas con la literatura y el periodismo sería interminable; buena parte de ellos ha alimentado la polémica expresando de un modo u otro su opinión sobre esta inveterada poligamia, desde la mordacidad del propio Hemingway, que consideraba que "trabajar en un

\footnotetext{
${ }^{3}$ Cabe reconocer el carácter pionero de una obra muy anterior: España fue noticia, de José Mario Armero (1976), sobre la que Preston basa su investigación.

${ }^{4}$ P. Preston (2008), p. 16.

${ }^{5}$ J. Acosta Montoro (1973), vol. 1, p. 51.

${ }^{6}$ J. M. Rodríguez Rodríguez y M. Anguelo Egea (2010), p. 9.
} 
periódico no perjudicará nunca a un joven y le podrá ayudar si se libera de esta ocupación en el momento oportuno", hasta el amor incondicional profesado por Gabriel García Márquez, quien en un discurso pronunciado en Los Ángeles en 1996 calificó al periodismo como el mejor oficio del mundo ${ }^{8}$.

Acaso el estudio más relevante sobre el tema sea Literatura y periodismo. Una tradición de relaciones promiscuas, de Albert Chillón. En los primeros capítulos, a partir de la idea de que todo el lenguaje es metafórico ${ }^{9}$, y por tanto, imaginativo, una obra creativa podríamos decir, Chillón difumina la frontera entre ficción y no ficción, pues todo acto lingüístico sería entonces una obra de ficción al ser establecido por medio de la facultad de representación del lenguaje:

[...] que al hablar, al decir, los sujetos inevitablemente ideamos, a saber, imaginamos la "realidad" que vivimos, observamos, evocamos o anticipamos; que toda dicción humana es, siempre y en alguna medida y manera variables, también ficción; que no es que uno de los modos posibles de la dicción sea la ficción junto a la llamada "no ficción" y sus géneros, pongamos por caso-, sino que dicción y ficción son constitutivamente una y la misma cosa; y que, en todo caso, la tarea reflexiva y analítica para el estudioso consiste en discernir cuáles son los grados y las modalidades en que esa ficción constitutiva de toda dicción se da en los intercambios comunicativos ${ }^{10}$.

${ }^{7}$ J. Acosta Montoro (1973), vol. 2, p. 257.

${ }^{8}$ G. García Márquez (2012), p. 105-18.

${ }^{9}$ Frente a la tradición estructuralista de Saussure que considera al lenguaje una herramienta del pensamiento, Chillón defiende la existencia de una "tradición relegada", formulada por primera vez por Wilhelm von Humboldt en 1805, que identifica lenguaje y pensamiento como un todo indisoluble. Numerosos filósofos de primera línea, entre los que se encuentran algunos como Heidegger, Wittgenstein, Bajtín o Gadamer, se han adentrado en la senda abierta por von Humboldt, considerando que la realidad proviene del lenguaje, y no viceversa. En Sobre verdad y mentira en sentido extramoral, Nietzsche halló una imagen reveladora y de gran hermosura: “¿Qué es, pues, la verdad? Un ejército móvil de metáforas, metonimias, antropomorfismos; en resumen, una suma de relaciones humanas, poética y retóricamente elevadas, transpuestas y adornadas, y que, tras largo uso, a un pueblo se le antojan firmes, canónicas y vinculantes; las verdades son ilusiones de las que se ha olvidado que lo son, metáforas que se han desgastado y han quedado sin fuerza sensorial; monedas que han perdido su imagen y ahora se toman en cuenta como metal, ya no como monedas. Seguimos siempre sin saber de dónde procede la tendencia a la verdad, pues hasta ahora sólo hemos oído hablar de la obligación que plantea la sociedad para existir: ser veraces, esto es, emplear las metáforas usuales; o sea, expresado moralmente, la obligación de mentir según una firme convención, de mentir en rebaño, en un estilo vinculante para todos." A. Chillón (1999), p. 27.

10 A. Chillón (1999), pp. 36-37. 
Esta premisa le permite establecer dos tipos de modalidades enunciativas: la enunciación facticia o ficción tácita (subdividida a su vez en la de tenor documental, donde incluye géneros periodísticos como la crónica o el reportaje, y la de tenor testimonial, donde se encuentra la literatura del yo), y la enunciación ficticia o ficción explícita (con tres subdivisiones: la de tenor realista, la de tenor fabulador o mitopoético y la de tenor falaz, todas en función de la mayor o menor pretensión fabuladora que haya en ellas) ${ }^{11}$. El acierto de esta visión abarcadora del acto de la escritura a partir de principios de carácter lingüístico radica en la posibilidad de estudiar la globalidad de los textos sin atender a distinciones poco funcionales, motivadas por prejuicios y vanidades de cada disciplina o por el peso de una tradición anquilosada y hermética que no se corresponde con la inagotable variedad de las distintas manifestaciones de la cultura escrita.

4. "He tenido una idea maravillosa: me voy a España, a la revolución española", escribe desde Nueva York el cubano Pablo de la Torriente Brau a su amigo Juan Marinello el 6 de agosto de 1936, a pocos días de comenzada la guerra ${ }^{12}$. En efecto, poco después ${ }^{13}$, con las credenciales de corresponsal de las revistas New Masses y El Machete en el bolsillo, Pablo de la Torriente atraviesa el Atlántico "con el gran bosque de su imaginación incendiado" (14) a fin de ser uno de los primeros latinoamericanos, si no el primero, en llegar a España para contarla y cantarla desde las trincheras republicanas.

A lo largo de sus catorce crónicas, se puede trazar el boceto de la España en guerra. El escritor y periodista recorre con euforia la revolucionaria Barcelona, entrevista a José Díaz y Francisco Galán o retrata el pueblo de Buitrago de Lozoya, donde "polemiza con el enemigo" en uno de sus textos más célebres (187-95). De hecho, la etiqueta de corresponsal pronto queda pequeña para él, que se siente incapaz de permanecer al margen y decide intervenir activamente en el conflicto ${ }^{14}$ : es nombrado Comisario Político del batallón del Campesino, un batallón de lo más literario, pues otro escritor, Miguel Hernández, ostenta allí el mismo cargo ${ }^{15}$. Como

\footnotetext{
${ }^{11}$ A. Chillón (1999), pp. 38-40.

${ }^{12}$ P. Torriente Brau (2005), p. 14.

${ }^{13}$ En una de sus cartas comenta su plan de tomar el barco Lafayette el 27 de agosto; no obstante, su hermana Zoe de la Torriente afirma que finalmente se embarca en el Ile de France el 1 de septiembre, como recoge Jorge Ferrer P. Torriente Brau (2011), p. 14.

${ }^{14}$ Él mismo presume en una de sus cartas de ser el primer periodista en convivir verdaderamente con los soldados: "Por cierto, que debo notificarte, no sin un poco de desprecio a tanta literatura falsificada como se está haciendo de la guerra en los periódicos, que, según me dijeron los milicianos y los oficiales de la columna, el primer periodista que subía con ellos, a pasarse las veinticuatro horas de guardia, había sido yo" (40).

${ }^{15}$ Entre la Alianza de Intelectuales y las misiones del frente, ambos traban una amistad que refrenda Miguel Hernández a la muerte de Pablo, dedicándole su "Elegía Segunda" de Vien-
} 
afirma Jorge Ferrer, "el corresponsal que iba a dar parte de la guerra se ha convertido él mismo en parte de la guerra"16. Pero a pesar de su actividad frenética, no deja de escribir y enviar crónicas, como la titulada "Cuatro muchachas en el frente", donde describe con brevedad y belleza a las jóvenes mujeres que luchan por la República:

Maruja tiene dieciocho años. Es la mayor de todas, pero parece la menor. Es pequeña, casi rubia, de grandes ojos infantiles. Le mataron el novio y el hermano y cayó ametrallada en la sierra de Guadarrama. Morirá en la montaña vengando a sus muertos. Ella dice que es la única manera de recordarlos. Y no siente el temor de la muerte. La vio tan pronto y la ha visto tan pródiga, que para ella ha perdido el prestigio del misterio. Es una muchacha del frente. Más pequeña que su fusil. Morirá en la montaña vengando a sus muertos. Y, sin embargo, sobre la tierra, muerta, parecerá, tan frágil, tan bonita, una paloma que cayó ${ }^{17}$.

Toda su correspondencia desde España es un monólogo enfebrecido ${ }^{18}$. Por un lado, refleja la pasión y el vértigo ante todo lo que está experimentando, la necesidad de suspender su rol de testigo para convertirse en protagonista y la maravilla que provoca en su ánimo el espectáculo de la revolución: "Sobre este cielo limpio y fino, que parece el cutis de una muchacha azul, brilla una luna que casi parece la de la bahía de La Habana, donde la tanta luz no deja dormir a los tiburones" (67). Por otro lado, lamenta con insistencia las bajas temperaturas a las que no consigue acostumbrarse ("Y de frío nada te digo. Moriré no de bala sino de frío", 105-06) y lamenta también el silencio de sus interlocutores: "No te he escrito en los últimos quince días. No he tenido tiempo para hacerlo, pero, además, como no he recibido ni una línea de ustedes, bien puedo permitirme escribir yo cuando buenamente pueda. No sé a qué atribuir esto" (114). Sus últimas palabras, del 13 de diciembre, aunque siempre dominadas por el buen ánimo, dejan caer un amargo reproche a la falta de respuesta del otro lado: "Recuerdos a todos aunque ninguno se acuerde de mandar una línea" (120). Cuando esta carta culmina su viaje al otro lado del Océano, Pablo ya está muerto. Ha caído en Majadahonda, peleando con los milicianos. Su cuerpo, tan frío como había presagiado, permanece varios días en campo enemigo hasta que puede ser rescatado. Cuando al fin lo recuperan, descubren (habría dicho César Vallejo) que su cadáver está lleno de mundo.

to del pueblo: "Me quedaré en España, compañero, / me dijiste con gesto enamorado / y al fin sin tu edificio tronante de guerrero / en la hierba de España te has quedado. [...]" $\mathrm{M}$. Hernández (1992), p. 100.

${ }^{16}$ P. Torriente Brau (2011), p. 16.

${ }^{17}$ P. Torriente Brau (2005), pp. 152-53.

${ }^{18}$ Niall Binns habla del "entusiasmo expresado en una prosa nerviosa, chispeante, que avanza a ritmo desbocado entre imágenes eléctricas, anáforas de agitada impaciencia y estribillos que delatan la pasión y las obsesiones del escritor”. N. Binns (2009), pp. 130-31. 
5. Confiesa el escritor argentino Martín Caparrós que le gusta que "en la palabra crónica aceche cronos, el tiempo. Siempre que alguien escribe, escribe sobre el tiempo, pero la crónica (muy en particular) es un intento siempre fracasado de atrapar el tiempo en que uno vive"19. Desde la Primera Crónica General de Alfonso X El Sabio a finales del siglo XIII hasta las dos antologías de crónicas latinoamericanas actuales que han sido publicadas en 2012 por Alfaguara y Anagrama, el viaje de este género misceláneo no se ha detenido ${ }^{20}$. Con el traje de la literatura, el periodismo o la Historia, bajo sus formas laxas se ha narrado toda suerte de acontecimientos: Hernán Cortés habló de las "mezquitas" del Nuevo Mundo y del esplendor inimaginable de Moctezuma, Antonio Pigafetta describió a los gigantes de Patagonia y las hojas que caminan alimentándose del aire, Daniel Defoe relató las penurias del año de la peste, y Truman Capote y Rodolfo Walsh diseccionaron brutales asesinatos. ¿Qué tienen en común las Crónicas de Indias con los textos emblemáticos del New Journalism norteamericano, las crónicas de guerra con el periodismo narrativo que se practica hoy día en América Latina? Parece evidente que el término se ha dilatado hasta hacerle amparar textos de diversa naturaleza; y, no obstante, en todos ellos subyace la intención de retener por medio de la escritura, y con un afán en mayor o menor medida estético, algunos sucesos significativos acaecidos en la vida real.

A pesar de su prodigalidad, el abandono de la crítica es evidente. Desde la óptica del periodismo, Manuel Bernal Rodríguez reconoce que "la crónica es la cenicienta" ${ }^{21}$ y que ha de situársela con un pie en la literatura y otro en el periodismo, "tanto que puede ser considerada como el eslabón que ilustra el proceso evolutivo que lleva desde el terreno exclusivo de la literatura al de la pura información ${ }^{22}$.

Desde el campo de la literatura, en el ensayo La invención de la crónica la venezolana Susana Rotker estudia la gestación del género durante el Modernismo en autores como José Martí o Rubén Darío. Un dato revelador: más de la mitad de la obra de Martí (13 de los 25 tomos de sus Obras Completas) corresponde a sus crónicas aparecidas en periódicos de toda América ${ }^{23}$, y sin embargo la esfera literaria ha relegado esta parte de su obra para recordarlo esencialmente como poeta ${ }^{24}$. Tras

\footnotetext{
${ }^{19}$ M. Caparrós (2012), p. 608.

${ }^{20}$ Según Manuel Bernal Rodríguez, que acude al Corominas, es la obra de Alfonso X la primera en recoger la palabra crónica, si bien es cierto que ya se encuentra en estado embrionario en los relatos de Jenofonte o el Antiguo Testamento M. Bernal Rodríguez (1997), pp. 9-10.

${ }^{21}$ M. Bernal Rodríguez (1997), p. 5.

${ }^{22}$ M. Bernal Rodríguez (1997), p. 39.

${ }^{23}$ S. Rotker (2005), p. 15.

${ }^{24}$ También Susana Rotker incide en el olvido que ha sufrido el género: "La crónica es un producto híbrido, un producto marginado y marginal, que no suele ser tomado en serio ni por la institución literaria ni por la periodística, en ambos casos por la misma razón: el
} 
el buceo por las hemerotecas y el análisis del contexto literario y cultural, Rotker ensaya una definición del género:

La crónica propone una épica con el hombre moderno como protagonista, narrado a través de un yo colectivo que procura expresar la vida entera, a través de un sistema de representación capaz de relacionar las distintas formas de existencia, explorando e incorporando al máximo las técnicas de escritura ${ }^{25}$.

Rotker defiende la calidad retórica de estos textos al tiempo que asume la transgresión de su trabajo, pues "no es sino transgresión y aventura aceptar que una nueva literatura pueda surgir desde un espacio periodístico" (225). Cabe objetar que antes de llegar al espacio periodístico, la crónica misma (o uno de sus múltiples y similares ancestros) provenía ya, como he afirmado, del espacio literario: la voluntad de aprehender la experiencia de los hechos de la realidad a través de las palabras se ha manifestado con diferentes disfraces en numerosos ámbitos de la escritura. En cualquier caso, establecer el completo árbol genealógico de la crónica, cuyo linaje parece haberse extendido vorazmente por todos los tiempos y lugares, constituye un titánico cometido todavía por desempeñar.

6. También el poeta argentino Raúl González Tuñón había abrazado la vanguardia en una mesa de Montparnasse y había declarado su amor a los puertos ${ }^{26}$. Con la politización de la literatura en los años treinta, Tuñón es uno de los primeros en empuñar la pluma como un arma. En 1935 reside en España durante unos meses, relacionándose con los poetas de la Generación del 27 y con Pablo Neruda, entre $\operatorname{otros}^{27}$; el año anterior se ha producido el levantamiento minero en Asturias, ferozmente aplastado por el entonces desconocido general Franco, consecuencia del cual son los poemas de La rosa blindada publicados en $1936^{28}$. Por tanto, cuando estalla

hecho de no estar definitivamente dentro de ninguna de ellas. Los elementos que una reconoce como propios y la otra como ajenos sólo han servido para que se la descarte, ignore o desprecie precisamente por lo que tiene de diferente" (225).

${ }^{25}$ S. Rotker (2005), pp. 229-30.

${ }^{26}$ Ambas imágenes corresponden al libro de poemas La calle del agujero en la media (1930).

${ }^{27}$ Años después afirmaría que se trató de un viaje "memorable en mi vida de poeta, de periodista, de hombre de mi tiempo, el que me dejó marcadas más vivencias" H. Salas (1975), p. 89.

${ }^{28}$ La importancia de este poemario queda de manifiesto en la carta que escribe en 1993 Octavio Paz a Eduardo Álvarez Tuñón, sobrino del poeta: "Para esa generación [la de los años treinta] escribir poesía combativa era escribir a la sombra de Raúl González Tuñón. Es el Rubén Darío de la poesía social y no cometo una herejía si afirmo que España en el corazón de Neruda y España aparta de mí este cáliz, de Vallejo, no hubieran podido ser sin $L a$ 
la guerra, González Tuñón es uno de los intelectuales más firmemente comprometidos, y así, en febrero de 1937, con la credencial de corresponsal en el bolsillo, se encuentra en un barco cruzando el Atlántico junto a su amigo Cayetano Córdova Iturburu (corresponsal a su vez del diario Crítica).

"La ruta del coraje" es el membrete que encabeza las crónicas numerosas del poeta que se publican en la revista argentina La Nueva España entre marzo y julio de 1937. En ellas, desde la frontera con Francia, Barcelona, Valencia o Madrid, Tuñón describe la violencia de la metralla y los obuses, el valor de la defensa de la cultura, los voluntarios y las canciones de los soldados, o los perfiles de intelectuales célebres y personajes casi anónimos, símbolos de la guerra. Si bien en muchas ocasiones el fervor revolucionario del argentino, plenamente identificado con la lucha de la República, quebranta la calidad literaria de sus textos, en ocasiones logra un gran resultado estético, como sucede con la crónica enviada desde Barcelona en la que describe la fundición del acero:

He visto los altos hornos, sí, los altos hornos de la Retaguardia, los Altos Hornos de la Revolución. Ríos de fuego, fuego redondo, fuego cuadriculado, lingotes de acero como sepulcros ardiendo, bosques de ladrillos, selvas de madera olorosa y el acero redondo, cuadrado, largo, corto, ancho, profundo, gracioso, temible, vencido, conquistado, convertido en granadas, en caños, en espoletas, y he visto los camiones blindados y he subido a un tren blindado, todo de colores como en los circos, al tren que pronto silbará por los campos de la victoria, al tren que ha salido de las manos obreras, íntegro, antifascista, unido, en el secreto terrible de sus tuercas ${ }^{29}$.

Llama la atención la escasa diferencia que existe entre todo lo que González Tuñón escribe en esta época: cartas personales, crónicas, prosas y poemas repiten los mismos motivos. Al mismo tiempo que en alguna de las crónicas se dirige a su mujer, como si se tratara de una carta ("Solamente puedo decir: Madrid [...] Estoy en Madrid. Amparito, ¿te acuerdas? Aquí vivimos con nuestros amigos. Aquí descubrimos juntos la gracia del mundo. ¡Hoy es Madrid la capital del mundo. ¡Qué bella está!”30), las cartas se publican como crónicas, eliminando las fronteras de lo privado y lo público ("Camarada: cómo he sentido que no estuvieras conmigo, en nuestro Madrid adorado, recorriendo los viejos lugares conocidos, evocando sombras queridas, acontecimientos, alegrías, penas" ${ }^{\prime 31}$ ). Lo mismo sucede con las crónicas y los poemas, pues en ocasiones aquellas funcionan como borradores de estos. La guerra

rosa blindada. Neruda lo reconoció con todas las letras y Vallejo hubiese hecho otro tanto si la muerte no lo hubiese sorprendido en París, en 1938”. P. Orgambide (1997), p. 119.

${ }^{29}$ La Nueva España, 4 de abril de 1937, p. 5.

${ }^{30}$ La Nueva España, 25 de abril de 1937, p. 5.

${ }^{31}$ La Nueva España, 18 de abril de 1937, p. 5. 
civil actúa en González Tunón como un acontecimiento desmedido que desordena los géneros y somete toda su escritura ${ }^{32}$.

7. A comienzos del siglo XX, la ciudad austral de Temuco reúne en la misma aula a dos niños que llegarían a ser dos poetas chilenos de fortuna dispar: Pablo Neruda y su amigo Juvencio Valle, a quien el primero denominará después "Juvencio Silencio" por su parquedad de palabra. En aquel tiempo, ambos desatienden la lección del profesor y sueñan versos, hasta que sus caminos se separan: Neruda se traslada a Santiago y parte a Oriente como diplomático, mientras que Juvencio se queda a vivir en un molino en su querido Sur de Chile, Sur del mundo ${ }^{33}$. En 1932, aunque ya ha publicado un poemario anterior, Juvencio Valle da a la imprenta los poemas de Tratado del Bosque, que son recibidos con displicencia por la crítica chilena encabezada por Alone; Neruda reconoce al compañero de la infancia y sale en su defensa ${ }^{34}$.

En 1938, invitado por la Alianza de Intelectuales Chilenos, Juvencio viaja a España como corresponsal de guerra ${ }^{35}$. En el mes de julio, la revista El Mono Azul

${ }^{32}$ En un breve texto de Las puertas del fuego (1938) titulado "Demasiada luz", se reproduce un diálogo entre el escritor y un interlocutor anónimo, que luego se denomina el "Espíritu de Castilla". Al ser preguntado por su oficio, González Tuñón contesta sencillamente que es "poeta" y la respuesta es la siguiente: "Entonces anda, mire, oye, y vuelve a América a hablarle a tus compatriotas de lo que has andado, visto y oído". R. González Tuñón (2011), p. 94. Poeta, o lo que es lo mismo: testigo y cronista.

${ }^{33}$ Así evoca Juvencio Valle sus días de infancia con Neruda: "Tuve el privilegio de conocerlo siendo un niño de seis años en Temuco; él era mi compañero de banco a pesar de ser yo mayor. Éramos unos niños que no corríamos, ni saltábamos, ni jugábamos a la pelota. Como él era muy chico, lo único que podía hacer era ponerse en un rincón para protegerse de esos salvajes que corrían de allá para acá y gritaban como locos. Él ahí en su rincón con pequeñas cosas, algún palo raro, insectos. Decía que tenía una pieza llena de objetos 'muy interesantes". L. Poirot (1987), p. 136.

34 “Juvencio Valle [...] es, sin embargo, por derecho de señorío lírico, por tensión y aumento de vida verbal; por condiciones esenciales y secretas, visibles, sin embargo en su estructura; por lo arbitrario, lo profundo y lo dulce y lo perfumado de su poesía es, digo, el poeta más fascinador y atrayente de la poesía actual de Chile" (El Mercurio, 20 de noviembre de 1932).

${ }^{35} \mathrm{Su}$ elección como corresponsal no satisface a todo el mundo. Los vanguardistas de $L a$ Mandrágora lo atacan ferozmente desde las páginas de su revista: "La Alianza de Intelectuales ha enviado a España a Juvencio Valle, uno de sus más representativos intelectuales, es decir un señor perfectamente cretino, perfectamente mediocre como escritor y como hombre. Sepan los soldados del glorioso ejército español que Juvencio Valle no representa a los intelectuales chilenos, puesto que en Chile él no hizo otra cosa que darse vueltas siguiendo la huella de su propia baba (Mandrágora, $\mathrm{n}^{\circ} 1$, diciembre de 1938, p. 15). 
publica un poema titulado "Piedras de Madrid"36 y una entrevista donde explica su concepción de la poesía, hasta entonces un canto intimista a la exuberancia de los bosques, como espejo de sus altibajos emocionales; en la entrevista afirma que "frente al hecho español, mi espíritu se estrella de lleno contra una realidad brutal y sangrienta, y aquí estoy tratando de desmontarme de un caballo que no sabe ponerse al paso del momento de vida o muerte que tenemos por delante"37.

A partir de entonces, en la revista chilena Ercilla comienzan a aparecer sus crónicas desde España. La primera visión de Barcelona lo conmociona y siente que la desmesura de la guerra invadirá su poesía: "Confieso que una corriente húmeda me comienza a correr por todo el cuerpo. Una fuerza violenta me sacude los nervios y me expulsa de mi abstracción. Mi plácida poesía campesina tiene ya, en su primera hora de España, su indeleble y estremecedor bautismo de fuego" ${ }^{\text {"38 }}$.

Precisamente, los textos de Juvencio Valle sobre la guerra revelan los efectos de la irrupción de un hecho descomunal en una mirada habituada a la contemplación de la Naturaleza; la pugna, al fin y al cabo, entre la vida y la muerte. En Barcelona, después de la visión de la sangre, busca el contacto con el campo y la hierba fresca para reponerse; el trayecto a Valencia es descrito como el paso por "el bíblico paraíso de los hombres"39; al llegar a Madrid, describe las golondrinas y los colores del crepúsculo. Prueba de ello es su crónica desde las trincheras de la capital:

Estoy en el oscuro corazón de la tierra. Y aquí no sólo veo producirse la muerte; veo también, con ojos maravillados, el imperceptible comienzo de la vida. Las raíces ciegas se alargan en la sombra y la gota cristalina se enlaza a los anillos temblorosos de la planta. Ahora me explico claramente de qué manera tan simple los árboles viejos echan brotes nuevos; sé por qué las flores se iluminan con los más vivos atributos del iris. Es que estoy viendo moverse las manos de la tierra. Veo sus uñas incesantes, su áspera boca nocturna. Aquí abajo se generan las grandes arquitecturas de la tierra. Mi sangre de campesino lo sabe y se precipita victoriosa como la savia en los troncos ${ }^{40}$.

Y, sin embargo, no siempre es así, y en ocasiones es la muerte la que sale victoriosa. Juvencio describe un bombardeo, del que huye "sujetándome el alma con las manos" ${ }^{\prime 1}$. Del mismo modo, cuenta cómo los campesinos escapan del fuego y la fertilidad de la tierra se rinde ante la destrucción: "El cielo tiene dinamita y en los

\footnotetext{
36 "Piedras nobles y vivas de Madrid, cómo sangran, / cómo lloran y cantan sus dolores terrestres; / cómo sufren la ruda embestida de los lobos, / las furiosas y negras descargas de las hachas" (El Mono Azul, 46, julio de 1938).

${ }^{37}$ El Mono Azul, 46, julio de 1938.

${ }^{38}$ Ercilla, 29 de julio de 1938, p. 6.

${ }^{39}$ Ercilla, 26 de agosto de 1938, p. 10.

${ }^{40}$ Ercilla, 12 de agosto de 1938, p. 6.

${ }^{41}$ Ercilla, 29 de julio de 1938, p. 6.
} 
rincones más inesperados espera la muerte. Hay que desconfiar hasta de los frutos de la tierra porque seguramente están llenos de pólvora mortífera" ${ }^{, 2}$.

8. Hasta aquí el trayecto, que sin embargo podría prolongarse. Un repertorio suficientemente abarcador (e incompleto) de cronistas de la guerra civil española entre los escritores hispanoamericanos debería incluir, además de los ya citados, a los cubanos Lino Novás Calvo, Nicolás Guillén, Juan Marinello, Carlos Montenegro, Alejo Carpentier, José Sánchez Arcilla, Rafael Suárez Solís, Manuel Millares Vázquez y Juan Breá; a los argentinos Cayetano Córdova Iturburu y José Gabriel; a los chilenos Vicente Huidobro y Carlos Vela Monsalve; a los uruguayos Alberto Etchepare y Wing (Luis Alfredo Sciutto); y al ecuatoriano Enrique Garcés. Como he insistido, queda un largo trabajo por acometer en las hemerotecas de Latinoamérica y España. Estas crónicas son un testimonio valioso de la Historia del siglo XX, sin duda, pero también y sobre todo páginas por incluir, brillantes en ocasiones, en la Historia de la Literatura Hispanoamericana que todavía no ha sido escrita.

\section{Obras citadas}

ACOSTA Montoro, José: Periodismo y literatura, 2 vols, Madrid, Ediciones Guadarrama, 1973.

BERNAL RODRÍGUEZ, Manuel: La crónica periodística. Tres aproximaciones a su estudio, Sevilla, Padilla Libros Editores \& Libreros, 1997.

BINNS, Niall: Voluntarios con gafas. Escritores extranjeros en la guerra civil española, Madrid, Mare Nostrum, 2009.

CAPARRÓs, Martín: "Por la crónica", en Antología de crónica latinoamericana actual, Madrid, Alfaguara, 2012.

CHILLÓN, Albert: Literatura y periodismo. Una tradición de relaciones promiscuas, Barcelona, Universidad Autónoma de Barcelona, 1999.

GARCíA MÁRQUEZ, Gabriel: Yo no vengo a decir un discurso, Barcelona, Mondadori, 2012.

GONZÁLEZ TUÑóN, Raúl: "La ruta del coraje", La Nueva España, Buenos Aires, 4 de abril de 1937, p. 5; 18 de abril de 1937, p. 5; 25 de abril de 1937, p. 5.

GONZÁLEZ TUÑóN, Raúl: La muerte en Madrid. Las puertas del fuego. 8 documentos de hoy, Buenos Aires, Beatriz Viterbo Editora, 2011.

HERNÁNDEZ, Miguel: Viento del pueblo, Madrid, Ediciones de la Torre, 1992. MANDRÁGORA, Santiago de Chile, diciembre de 1938, p. 15.

NerUdA, Pablo, El Mercurio, Santiago de Chile, 20 de noviembre de 1932.

${ }^{42}$ Ercilla, 26 de agosto de 1938, p. 10. 
Orgambide, Pedro: Recordando a Tuñón. Testimonios, ensayos y poemas (ed.), Buenos Aires, Ediciones Instituto Movilizador de Fondos Cooperativos, 1997. POIROT, Luis: Neruda: retratar la ausencia, Madrid, Comunidad de Madrid, 1987.

PRESTON, Paul: Idealistas bajo las balas. Corresponsales extranjeros en la guerra de España, Barcelona, Mondadori, 2008.

RodRíGuEZ RodríGUEZ, Jorge Miguel y María ANGULO EgEA: "Introducción: Nuevas miradas sobre una vieja tradición periodístico-literaria", en Periodismo literario. Naturaleza, antecedentes, paradigmas y perspectivas, Madrid, Fragua, 2010.

ROTKER, Susana: La invención de la crónica, México, FCE, 2005.

SALAS, Horacio: Conversaciones con Raúl González Tuñón, Buenos Aires, La Bastilla, 1975.

TORRIENTE BraU, Pablo de la: Cartas y crónicas desde España, La Habana, Ediciones La Memoria, 2005.

Torriente BraU, Pablo de la: Peleando con los milicianos, Madrid, Verbum, 2011.

VALle, Juvencio, "Hablando con Juvencio Valle", El Mono Azul, 46, julio de 1938.

VALLE, Juvencio, Ercilla, Santiago de Chile, 29 de julio de 1938, p. 6; 12 de agosto de 1938, p. 6; 26 de agosto de 1938, p. 10. 